\title{
REVIEW
}

\section{Advances in chronohaematology}

\section{Josef Berger}

Faculty of Health and Social Studies, University of South Bohemia, České Budějovice, Czech Republic

Received $26^{\text {th }}$ March 2008.

Revised $25^{\text {th }}$ May 2008.

Published online $2^{\text {nd }}$ June 2008.

\begin{abstract}
Summary
The circadian rhythms of the haemato-immune system seem to be synchronized by two clocks: the hypothalamic endogenous, and the exogenous which is based on environmental stimuli. The suprachiasmatic nucleus is not only a circadian clock, it also synchronizes peripheral oscillators and integrates light information through the retino-hypothalamic tract. The role of the "peripheral" clock genes in mature leucocytes still remains an unanswered question as well as the role of clock proteins in "non-clock" physiology. The circadian rhythms may be a basis for circannual variations, although the molecular bases of such rhythms remain a mystery. There are several hormones which have a significant impact on haematological characteristics; the finding of a lower superoxide release from granulocytes at higher melatonin levels opens up new research opportunities for melatonin therapy. Discrepancies between circadian changes in mRNAs and the appropriate protein participating in haemocoagulation and fibrinolysis may indicate that we do not know their control processes or their genetic background well, although this problem has now opened up a new area for pharmacological research. The endogenous clock facilitates an alternation in the immune system which counters external attacks in daytime and induces repair and development by night.
\end{abstract}

Keywords: circadian - seasonal - clock gene - haemostasis - immunity - melatonin - superoxide

\section{INTRODUCTION}

A biorhythm is a periodically repeated change in living systems. It is a time-keeping system that anticipates environmental alterations. The rhythms most studied are circadian, with a period of about

Josef Berger, Faculty of Health and Social Studies, University of South Bohemia, Emy Destinové, 37005 České Budějovice, Czech Republic

매뵤 berger@zsf.jcu.cz

용 +420389037617
$24( \pm 2) \mathrm{h}$. The mechanism of biorhythm control has now been intensively studied at the molecular, cellular and organism levels for some tens of years. The circadian rhythms have most often been described in terms of their phases and amplitudes, and how these respond, in both health and disease, to a single exposure to synchronisers.

There is a reciprocal relationship between the robustness of the endogenous circadian timing system and its dependency on regularly timed synchronisers (light, physical activity, and feeding); this relationship can be damaged during disease or by ageing (Van Sommeren et al. 2007). Eventual therapeutic intervention can also embrace circadian synchronisation (cf. Lader 2007, Maharaj et al. 2007). 
In addition to circadian rhythms, there are important circannual variations and many more new frequencies, with the newest being an 0.42 year periodicity not only in solar flares and in solar activity generally and in sudden cardiac death (Halberg et al. 2006), but even in the circulating melatonin of patients.
The aim of this contribution is to choose and highlight the advances in chronohaematology (Halberg et al. 2003, Berger 2006) in the two years after our last review of this topic.

\section{Table 1. Summarizing table that conveys main areas of advances in chronohaematology during last two years}

Clock control

two clocks system

environmental changes

suprachiasmatic nucleus and peripheral oscillators

photic and nonphotic synchronization

Molecular timing

the role of genes in timing

per genes in cancer development

clock proteins in "non-clock" physiology

Haemato-immune rhythms

hypothalamo-immune comunication

genetic background

melatonin synchronization

correlation between activity of antioxidant enzymes and hormones

circadian changes in leucocyte and erythrocyte functions

stem cell harvest

Hemostasis

the risk state of thromboembolic events

clock genes control

\section{CLOCK CONTROL}

Recent studies suggest that the control system of the circadian rhythm is composed of two parts: the rigid master circadian clock and the more flexible peripheral oscillators (Berger 2004a, Kronfeld-Schor and Dayan 2008). Mammals, including humans, synchronize the master clock in the brain (Ko and Tkahashi 2006) to environmental changes through photic stimuli or the little known non-photic entrainment (Halberg et al. 1953, Cornelissen et al. 2007, Salazar-Juarez et al. 2007, Challet 2007, Mendoza 2007, Novak et al. 2008).

The circadian rhythms of the haemato-immune system seem to be synchronized by two clocks, the first of which is endogenous, based on clock gene activity in the suprachiasmatic nucleus. The second is exogenous, based on environmental immune stimuli (Berger 2004a). Interactions between these two clocks can explain both the frequently observed individual differences in circadian rhythms and the more subtle role of the clock genes in peripheral organs (Berger 2008).

The endogenous clock facilitates an alternation in the immune system which counters external attacks in daytime and induces repair and development by night. The suprachiasmatic nucleus is not only a circadian clock, it also synchronizes peripheral oscillators and integrates light information through the retino-hypothalamic tract (Lamont et al. 2007). Shift work and jet lag, which modify circadian rhythms, may be factors contributing to an increase in certain cancers, cardiovascular, gastrointestinal disease, reproductive difficulties and mortality (Mormont et al. 2000, Haus and Smolensky 2006, James et al. 2007a, Lamont et al. 2007).

The circadian rhythms may be the bases of circannual variations with a period about 1 year ( \pm 2 months). Vertebrates can anticipate seasonal 
changes in weather using a set of interconnected neural elements (retina, hypothalamus, pineal melatonin production and receptors in mammals) and endocrine elements (prolactin secreting cells in mammals) that govern photoperiodic responses (Hazlerigg and Wagner 2006, Lincoln et al. 2006). Seasonal photoperiodism facilitates transition from winter to summer phenotypes, physiology and behaviour (Wagner et al. 2007).

Many seasonal changes in the laboratory characteristics (Berger 1980a, Haus 1996, Sher et al. 2005, Kiank et al. 2007) and behaviour of both human and animal subjects cannot however be explained by the above mentioned circannual mechanism. The molecular bases of the control of circannual rhythms remain a mystery.

\section{MOLECULAR TIMING}

Some oscillator components in animals may be related to tumour growth and it is known that per genes can suppress tumour growth or formation $(\mathrm{Fu}$ et al. 2002, Chen et al. 2005, Gery et al. 2006, Krugluger et al. 2007, Lamont et al. 2007, Zeman et al. 2008). Circadian proteins such as BMAL play a role in age-related pathologies (Kondratov 2007). The clock gene mutant in laboratory mice has increased tumours ( $\mathrm{Fu}$ et al. 2002). A proper relationship between the rhythmic expression of clock components and their absolute values may play a role in cancer development, and their deficit or absence may negatively influence the progress of the disease (Zeman et al. 2008). Clock genes also play a role in mental disorders (Lamont et al. 2007).

Historically, the molecular mechanisms of circadian rhythms have been studied in micro-organisms and Drosophila because the entire circadian system can be contained in a single cell. The transcription/translation feedback model in micro-organisms (Lakin-Thomas and Brody 2004, Lakin-Thomas 2006) reflects an evolutionary conserved mechanism and may therefore give us insight into the molecular basis in both prokaryotic and eukaryotic organisms.

Circadian rhythms are generated by molecular clock genes whose proteins rhythmically modulate transcription of nearly $10 \%$ of the genome: the so-called clock 'controlled' genes (Tsinkalovsky et al. 2006, for review). Mammalian clock genes are active in both the hypothalamus central clock and peripheral tissues including human blood cells (Berger 2006, Tsinkalovski 2005, 2007, James et al. 2007b, Dardente and Cermakian 2007, Haus 2007a, for review). The second and third control points of clock gene regulation represent post-translational modifications of the clock proteins and chromatin remodelling (Dardente and Cermakian 2007).

It has been hypothesized that cell cycle points are gated to an intrinsic circadian clock for protection from circadian exposure to mutagens, e.g., UV radiation peaks with daylight and dissolved genotoxins that fluctuate with feeding periods (Shadan 2007). Perhaps, we can now following publication of the literature summarised above - look forward to the discovery of a new role for clock proteins in "non-clock" cellular physiology.

\section{HAEMATO-IMMUNE OSCILLATIONS}

Circadian changes in circulating blood cells have been recognized in various species and ages (Haus 1996, Berger 2004b). Cerutti and co-workers (2006) described the creation of the circadian during ontogenesis of calves. Circadian rhythms in the number of mammalian leucocytes can reflect oscillations in haematopoietic proliferation activity in the bone marrow (Berger 1980b, Smaaland et al. 1992). Recent findings show that haematopoietic stem cells also exit the bone marrow into the periphery in a circadian rhythm with a peak at five hours of light (Alcivar 2008). Clinicians may now need to pay attention to the time of day in which they harvest stem cells from the blood.

Last year, Ohkura with co-workers (2007a) revealed the influence of different genetic backgrounds on the circadian rhythmicity of leucocytes, erythrocytes and erythropoietin. Periodic changes in the number of peripheral blood cells can influence their functions. The fact that the autonomous nervous system and the neuroendocrine system have been shown to modulate leucocyte physiology supports the concept that circadian timing is an important aspect of hypothalamo-immune communication (Arjona and Sarkar 2008).

There are several hormones which have a significant impact on haematological characteristics one of the more important of which is melatonin which regulates and synchronizes many circadian rhythms (Haus 2007a).

Circadian and circannual variations in erythropoietin production and release, stimulate rhythms in erythropoietic proliferation (Gunga et al. 2007) but there are some papers that demonstrate, and others that simply did not find, a rhythm in 
erythropoietin activity. Further research on this topic is desirable.

Melatonin plays an important role in the regulation of various body and cellular functions including immunity. It can induce changes in the intracellular calcium concentration that modulates proliferation and its circadian alteration (Wronka et al. 2008). This hormone serves as an inhibitor of myeloperoxidase which catalyses oxidant formation, which has been implicated in both immune reactions and the pathogenesis of various diseases. It modulates the formation of myeloperoxidase intermediates (Galijasevic et al. 2008). It prevents inflammation and oxidative stress and the circadian rhythm of the melatonin level correlates with variations in both neutrophil accumulation and its protective effect (Guney et al. 2007).

The endogenous level of melatonin is highest during the night or during the second half of the night - it is the so-called 'nocturnal' hormone - and higher melatonin levels are associated with better sleep. Ageing changes these rhythms; in older individuals, treatment with melatonin and tryptophan at the concentrations and times of administration considered suitable for improved nocturnal rest also reverses the immuno-suppressory and oxidative effects accompanying phagocytosis (Paredes et al. 2007).

Human leucocyte reactive oxygen species show circadian variations and they might possibly influence the occurrence of cardiovascular incidents (Larsen and Lyberg 2006). The finding of lower superoxide release from granulocytes at higher melatonin levels opens up new research opportunities for melatonin therapy (Geron et al. 2006). Some patients with low melatonin activity may benefit from both improvement in their sleep quality and a reduction of granulocyte mediated oxidative stress after melatonin administration.

Superoxide dismutase activity in erythrocytes changes the circadian rhythm in correlation with corticosteroid levels, although other enzymes participating in oxidative stress seem to be rather constant (Goncharova et al. 2006). It seems that hormones melatonin and corticosteroids play an essential role in the regulation of superoxide dismutase activity which is assumed to participate in many cellular processes.

Following the dissociation of sleep from the effects of circadian rhythms it has been documented that sleep alone can enhance adaptive immune responses. Sleep is associated with an increase in pre-dendritic cells, i.e. myeloid dendritic cell precursors, producing interleukin-12, activity of interleukin-6 (but not the concentration of monocytes producing this cytokine) and decreased numbers of CD14(dim)CD16+ and interleukin-10, producing monocytes, plasmacytoid dendritic cells and T cells (Lange et al. 2006, Dimitrov et al. 2006, 2007). Sleep alone enhances adaptive immunity and stimulates circadian alterations in immunity, but high prolactin and low cortisol levels also contribute to some of these changes during sleep.

Lymphocytes and neutrophils participate in allergic-inflammatory processes. One of the effects of their activation is increased binding to histamine which reaches a peak in the afternoon for healthy subjects' and is lowered in the night, while their amplitude in asthmatic subjects was not significant (Zak-Nejmark et al. 2006). The different circadian histamine binding to leucocytes in atopic from healthy subjects may participate in the nocturnal exacerbation of disease symptoms.

Erythrocyte superoxidase, catalase and glutathione peroxidise show seasonal variations (Balog et al. 2006) which can be important in relation to the circannual rhythm in oxidative stress and cardiovascular events (cf. Touitou and Bogdan 2007). Circannual rhythms in the enzymes of oxidant-antioxidant balance can be positively influenced following regular physical activity (Balog et al. 2006). New results (Yerer and Aydogan 2006) have revealed rhythms in erythrocyte deformability, one of the impact factors participating in the rhythms of cardiovascular events.

A significant leucocytosis after elevated cortisol concentration has been noted several times, recently in horses by Quaranta et al. (2006): training programmes must consider the circadian rhythms of cortisol as its elevated concentration can cause stress disease and the 'overtraining' syndrome. Cortisol has an important immunosuppressive activity and its alternations could be considered to be the ground of the circadian rhythm in the circulating lymphocyte count. No similar correlation was found in colorectal cancer patients (Mussi et al. 2006).

In summary, new details concerning oscillations in blood cells have been brought to light in the last two years, while the chronobiology of haematopoiesis has concentrated on clock gene activity.

\section{HAEMOSTASIS}

The haemostatic system has multiple components in an intricate organization; the interaction of the 
rhythms of the variables participating in haemostasis determine the transient risk states of thromboembolic events, including myocardial infarction and stroke, and of haemorrhage and haemorrhagic events, each with a unique timing and coinciding with rhythms in fibrinolytic activity (Haus 2007b, for review). It is has been known for many years that the myocardial infarction peak usually occurs in the morning between 7 and 12 a.m. (Touitou and Bogdan 2007). Ohkura and co-workers (2007b) have described circadian rhythms in the plasma plasminogen activator inhibitor-1 in all examined mice strains, and in plasma antithrombin and protein $\mathrm{C}$ only in the strain Jcl:ICR, whereas plasma prothrombin, factor VII, X, prothrombin time and activated partial thrombin time remained constant in all strains. They also found circadian fluctuations of mRNA, although an appropriate coagulation factor expresses constant activity. The clock gene was found to be involved in the regulation of fibrinolysis through plasminogen activator inhibitor-1 production (Oishi et al. 2005, 2006).

The CLOCK protein forms heteredimers with BMAL1 and then activates another clock gene via E-box elements in their promoters (Reppert and Weaver 2002). Understanding the molecular mechanism of plasminogen activator inhibitor-1 alterations could lead to the discovery of new pharmaceutical targets (Oishi et al. 2006). A new research area could be found in the mechanism of the coagulation and fibrinolytic system.

\section{CONCLUSION}

The circadian rhythms of the haemato-immune system are synchronized by two clocks. The suprachiasmatic nucleus also synchronizes peripheral oscillators and integrates light information through the retino-hypothalamic tract. Current findings indicate the important role of "peripheral" clock genes in the immune system but the role of clock genes in mature leucocytes is unknown. The molecular bases of circannual rhythms also remain a mystery.

Melatonin and erythropoietin have a significant impact on rhythms. The autonomous nervous system and the neuroendocrine system have been shown to modulate leucocyte physiology and this supports the concept of circadian timing as an important aspect of hypothalamo-immune communication. The different circadian histamine binding to leucocytes in atopic from healthy subjects may participate in the nocturnal exacerbation of disease symptoms. Some oscillator components in animals may be related to tumour growth.

The interactions among the rhythms of the variables participating in haemostasis determine transient risk states of thromboembolic events. Discrepancies between circadian changes in mRNAs and appropriate proteins participating in haemocoagulation and fibrinolysis indicate that we do not know the control of these processes or their genetic background well.

\section{ACKNOWLEDGEMENTS}

This work was partially supported by grant no 1697/07 from the Ministry of Education of the Czech Republic.

\section{REFERENCES}

Alcivar A: Stem cell rhythm. Nature Med. 14:252, 2008.

Arjona A, Sarkar DA: Circadian oscillations of clock genes, cytolytic factors, and cytokines in rat NK cells. J. Immunol. 174:7618-7624, 2005.

Arjona A, Sarkar DA: Evience supporting a circadian control of natural killer cell function. Brain Behav. Immunol. 20:469-476, 2006.

Arjona A, Sarkar DA: Are circadian rhythms the code of hypothalic-immune communication? Insight from natural killer cells. Neurochem. Res. 33:708-718, 2008.

Balog T, Sobočanec S, Šverko V, Krolo I, Ročić B, Marotti M, Marotti T: The influence of season on oxidant-antioxidant status in trained and sedentary subjects. Life Sci. 78:1441-1447, 2006.

Berger J: Seasonal influences on circadian rhythms in the blood picture of laboratory mice, Part I: leucocytes and erythrocytes, Part II: lymphocytes, eosinophils and segmented neutrophils. Z. Versuchstierkd. 22:122-134, 1980a.

Berger J: Leucokinetic study. Morphology of the bone marrow and blood after experimental induction of marrow hypoplasia by cyclophosphamide in laboratory rats. Fol. haematol. 107:862-877, 1980b.

Berger J: Regulation of circadian rhythms. J. Appl. Biomed. 2:131-140, 2004a. 
Berger J: Chronohaematology. J. Appl. Biomed. 2:179-185, 2004b.

Berger J: Current progress in chronohaematology. J. Appl. Biomed. 4:111-114, 2006.

Berger J: A two-clock model of circadian timing in the immune system of mammals. Path. Biol. 56: doi:10.1016/j.patbio.2007.10.001, 2008.

Boivin DB, James FO, Wu A, Cho-Park PF, Xiong $\mathrm{H}$, Sun ZS: Circadian clock genes oscillate in human peripheral blood mononuclear cells. Blood 102:4143-4145, 2003.

Cerutti RD, Scaglione MC, Tarabla HD, Boggio JC: Biological rhythm of leukocyte concentration in calves under natural conditions. Biol. Rhythm Res. 37:451-454, 2006.

Challet E : Entrainment of the suprachiasmatic clockwork in diurnal and nocturnal mammals. Endocrinology 148:5648-5655, 2007.

Chen ST, Choo KB, Hou MF, Yeh KT, Kuo SJ, Chang JG: Deregulated expression of the per1, per2 and per3 genes in breast cancers. Carcinogenesis 26:1241-1246, 2005.

Cornélissen G, Halberg F, Zeman M, Jozsa R, Tarquini R, Perfetto F, Salti R, Bakken EE: Toward a chronome (time structure) of emlatonin. In Pandi-Perumal SR, Cardinali DP (eds): Melatonin: from Molecules to Therapy. Nova Biomed. Books, New York, p.135-176, 2007.

Dardente H, Cermakian N: Molecular circadian rhythms in central and peripheral clocks in mammals. Chronobiol. Int. 24:195-213, 2007.

Dimitrov S, Lange T, Benedict C, Nowell MA, Jones SA, Scheller J, Rose-John S, Born J: Sleep enhances IL-6 trans-signaling in humans. FASEB J. 20:2174-2176, 2006.

Dimitrov S, Lange T, Nohroudi K, Born J: Number and function of circulating human antigen presenting cells regulated by sleep. Sleep 30:401-411, 2007.

Filipski E, King VM, Etienne MC, Li XM, Claustrat B, Granda TG, Milano G, Hastings MH, Levi F: Persistent twenty-four hour changes in liver and bone marrow despite suprachiasmatic nuclei ablaton in mice. Am. J. Physiol. Regul. Integr. Comp. Physiol. 287:R844-851, 2004.

Fu L, Pelicano H, Liu J, Huang P, Lee C: The circadian gene Priod 2 plays an important role in tumour suppression and DNA damage response in vivo. Cell 111:41-50, 2002.

Fukuya H, Emoto N, Nonaka H, Yagita K, Okamura H, Yokoyama M: Circadian expression of clock genes in human peripheral leukocytes. Biochem. Biophys. Res. Commun.
354:924-928, 2007.

Galijasevic S, Abdulhamid I, Abu-Soud HM: Melatonin is a potent inhibitor for myeloperoxidase. Biochemistry 47:2668-2677, 2008.

Geron R, Shurtz-Swirski R, Sela S, Gurevitch Y, Tanasijtschouk T, Orr ZS, Shkolnik GS, Tanhilevski O, Kristal B: Polymorphonuclear leucocyte priming in long intermittent nocturnal haemodialysis patients - is melatonin a player? Nephrol. Dial. Transplant. 21:3196-3201, 2006.

Gery S, Komatu N, Baldjyan L, Yu A, Koo D, Koeffler HP: The circadian gene Per1 plays an important role in cell growth and DNA damane control in human cancer cells. Mol. Cell. 22:375-382, 2006.

Goncharova ND, Shmaliy AV, Bogatyrenko TN, Koltover VK: Correlation between activity of antioxidant enzymes and circadian rhythms of corticosteroids in Macaca mulatta monkeys of different age. Exp. Gerontol. 41:778-783, 2006.

Guney Y, Hicsonmez A, Uluoglu C, Guney HZ, Turkcu UO, Také G, Yucel B, Caglar G, Bilgihan A, Erdogan D, Andreu MN, Kurtman C, Zengil H: Melatonin prevents inflammation and oxidative stress caused by abdominopelvic and total body irradiation of rat small intestine. Braz. J. Med. Biol. Res. 40:1305-1314, 2007.

Gunga HC, Kirsch KA, Roecker L, Kohlberg, Tiedemann J, Steinach M, Schobersberger W: Erythropoietin regulation in humans under different environmental and experimental conditions. Resp. Physiol. Neurobiol. 158:287-297, 2007.

Halberg F, Visscher MB, Bittner JJ: Eosinophil rhythm in mice: range of occurrence; effects of illumination, feeding and adenalectomy. Am. J. Physiol. 174:109-122, 1953.

Halberg F, Cornélissen G, Katinas G, Syutkina EV, Sothern RB, Zslavskaya R, Halberge Francine, Watanabe Y, Schwarzkopff O, Otsuka K, Tarquini R, Frederico P, Siggelová J: Transdisciplinary unifying implications of circadian findings in the 1950s. J. Circadian Rhythms 1:2(p.1-61), 2003.

Halberg F, Cornélissen G, Katinas G, Tvildiani L, Gigolashvili M, Janashia K, Toba T, Revilla M, Regal P, Sothern RB, Wendt HW, Wang Z, Zeman M, Jozsa R, Singh RB, Mitsutake G et al.: Chronobiology's progress. Part I, season's appreciations 2004-2005: time-, frequency-, phase-, variable-, individual-, age- and sitespecific chronomics. J. Appl. Biomed. 4:1-38, 2006. 
Haus E.: Biologic rhythms in hematology. Pathol. Biol. 44:618-630, 1996.

Haus E: Chronobiology in the endocrine system. Adv. Drug Delivery Rev. 59:985-1014, 2007a.

Haus E: Chronobiology of hemostasis and inferences for the chronotherapy of coagulation disorders and thrombosis prevention. Adv. Drug Deliv. Rev. 59:966-984, 2007b.

Haus E, Smolensky M: Biological clocks and shift work: circadian dysregulation and potential long-term effects. Cancer Causes Control 17:489-500, 2006.

Hazlerigg DG, Wagner GC: Seasonal photoperiodism in vertebrates: from coincidence to amplitude. Trends Endocrinol. Metab. 17:83-91, 2006.

James FO, Cermakian N, Boivin DB: Circadian rhythnms of melatonin, cortisol, and clock gene expression during simulated night shift work. Sleep 30:1427-1436, 2007a.

James FO, Boivin DB, Charbonneau S, Bélanger V, Cermakian $\mathrm{N}$ : Expression of clock genes in human peripheral blood mononuclear cells throughout the sleep/wake and circadian cycles Chronobiol. Int. 24:1009-1034, 2007b.

Kiank C, Koerner Pia, Ke3ler W, Traeger T, Maier S, Heidecke CD, Schuett C: Seasonal variations in inflammatory responses to sepsis and stress in mice. Crit. Care Med. 35:2352-2358, 2007.

Ko CH, Takahashi JS: Molecular components of the mammalian circadian clock. Hum. Mol. Genet. 15:R271-R277, 2006.

Kondratov RV: A role of the circadian system and circadian proteins in aging. Ageing Res. Rev. 6:12-27, 2007.

Kronfeld-Schor N, Dayan T: Activity patterns of rodents: the physiological ecology of biological rhythms. Biol. Rhythm Res. 39:193-211, 2008.

Krugluger W, Brandstaetter A, Kállay E, Schueller J, Krexner E, Kriwanek S, Bonner E, Cross HS: Regulation of genes of the circadian clock in human colon cancer: reduced period-1 and dihydropyrimidine dehydrogenase transcription correlates in high-grade tumors. Cancer Res. 67:7917-7922, 2007.

Lader M: Limitations of current medical treatments for depression: disturbed circadian rhythms as a possible therapeutic target. Eur. Neuropsychopharmacol. 17:743-755, 2007.

Lakin-Thomas PL: New model for circadian systems in microorganisms. FEMS Microbiol. Lett. 259:1-6, 2006.

Lakin-Thomas PL, Brody S: Circadian rhythms in microoranisms: new complexities. Annu. Rev.
Microbiol. 58: 489-519, 2004.

Lamont EW, Legault-Coutu D, Cermakian N, Boivin DB: The role of circadian clock genes in mental disorders. Dialogues Clin. Neurosci. 9:333-342, 2007.

Lange T, Dimitrov S, Fehm HL, Westermann J, Born J: Shift of monocyte function toward cellular immunity during sleep. Arch. Intern. Med. 166:1695-1700, 2006.

Larssen KS, Lyberg T: Oxidative status - Age- and circadian variations? A study in leukocytes/plasma. Neuroendocrinol. Lett. 27:445-452, 2006.

Lincoln GA, Clarke IJ, Hut RA, Hazlerigg DG: Characterizing a mammalian circannual pacemaker. Science 314:1941-1944, 2006.

Maharaj DS, Glass BD, Daya S: Melatonin: new places in therapy. Biosci. Rep. 27:299-320, 2007.

Mendoza J: Circadian clocks: setting time by food. J. Neuroendocrinol. 19:127-137, 2007.

Mormont MC, Waterhouse J, Bleuzen P, Giacchetti S Jami A, Bodan A, Lellouch J, Misset JL, Touitou Y, Levi F: Marked 24-h rest/activity rhythms are associated with better quality of life, better response, and longer survival in patients with metastatic colorectal cancer and good performance status. Clin. Cancer Res. 6:3038-3045, 2000.

Mussi C, Crippa S, Bonardi C, Fontana A, Caprotti R, Uggeri F: Endocrine and immunological alterations during cancer processes. Int. Surg. 91:68-71, 2006.

Novak CM, Ehlen JC, Albers HE: Photic and nonphotic inputs to the diurnal circadian clock. Biol. Rhythm Res. 39:291-304, 2008.

Ohkura N, Oishi K, Sekine Y, Atsumi G, Ishida N, Matsuda J, Horie S: Comparative study of circadian variations in numbers of peripheral blood cells among mouse strains: unique feature of $\mathrm{C} 3 \mathrm{H} / \mathrm{HeN}$ mice. Biol. Pharm. Bull. 30:1177-1180, 2007a.

Ohkura N, Oish K, Sakata T, Kadota K, Kasmatsu M, Fukushirna N, Kurata A, Tamai Y, Shira H, Atsumi GI, Ishida N, Matsuda J, Horie $\mathrm{S}$ : Circadian variations in coagulation and fibrinolytc factors among four different strains of mice. Chronobiol. Int. 24:651-669, $2007 \mathrm{~b}$.

Oishi K, Ohkura N, Amagai N, Ishida N: Involvement of circadian clock gene Clock in diabetes-induced circadian augmentation of plasminogen activator inhibitor-1 (PAI-1) expression in the mouse heart. FENS Lett. 579:3555-3559, 2005.

Oishi K, Ohkura N, Wakabaashi M, Shirai H, 
Sato K, Matsuda J, Atsumi G, Ishida N: Clock is involved in obesity-induced disordered fibrinolysis in ob/ob mice by regulating PAI-1 gene expression. J. Thromb. Haemost. 4: 1774-1780, 2006.

Paredes SD, Terron MP, Marchena AM, Barriga C, Pariente JA, Reiter RJ, Rodriguez AB: Effect of exogenous melatonin on viability, ingestion capacity, and free-radical scavenging in heterophils from young and old ringdoves (Streptopelia risoria). Mol. Cell. Biochem. 304:305-314, 2007.

Quaranta A, Tateo A, Siniscalchi M, Padalino B, Iacoviello $\mathrm{R}$, Centoducati P: Influence oftraining on cortisol plasma levels and other hematic parameters in standardbred trotters. Ippologia 17:5-10, 2006.

Reppert SM, Weaver DR: Coordination of circadian timing in mammals. Nature 418:935-941, 2002.

Salazar-Juarez A, Parra-Gamez L, Mendez SB, Leff P, Anton B: Non-photic entrainment. Physiological mechanism. Part II. (in Spanish) Salud Mental 30:69-79, 2007.

Shadan FF: Circadian tempo: a paradigm for genome stability? Med. Hypoth. 68:883-891, 2007.

Sher L, Oquendo MA, Galfalvy HC, Zalsman G, Cooper TB, Mann JJ: Higher cortisol levels in spring and fall in patients with major depression. Progr. Neuro-Psychopharmacol. Biol. Psychiatry 29:529-534, 2005.

Smaaland R, Lacrum O, Sothern R, Sletvold O, Bjerknes $\mathrm{R}$, Lote $\mathrm{K}$ : Colony forming unit-granulocyte-macrophage and DNA synthesi of human bone marrow are circadian stage-dependent and show covariation. Blood 79:2281-2287, 1992.

Touitou Y, Bohdan A: Circadian and seasonal variations of physiological and biochemical determinats of acute myocardial infarction. Biol. Rhythm Res. 38:169-179, 2007.

Tsinkalovsky O, Rosenluind B, Lacrum OD, Eiken HG: Clock gene expression in purified mouse hematopoietic stem cells. Exp. Hematol. 33:100-107, 2005.

Tsinkalovsky O, Filipski E, Rosenlund B, Sothern RB, Eiken HG, Wu MW, Claustrat B, Bayer J, Lévi F, Laerum OD: Circadian expression of clock genes in purified hematopoietic stem cells is developmentally regulated in mouse bone marrow. Exp. Hematol. 34:1249-1261, 2006.

Tsinkalovsky O, Smaaland R, Rosenlund B, Sothern RB, Hirt A, Steine S, Badiee A, Abrahamsen JF, Eiken HG, Lacrum OD: Circadian variations in clock gene expression of human bone marrow CD34(+) cells. J. Biol. Rhythms 22:140-150, 2007.

Van Someren EJW, Riemersma-Van Der Lek RF : Live to the rhythm, slave to the rhythm. Sleep Med. Rev. 11:465-484, 2007.

Wagner GC, Johnson JD, Clarke IJ, Lincoln GA, Hazlerigg DG: Redefining the limits of day length responsiveness in a seasonal mammal. Endocrinology 149:32-39, 2007.

Wronka M, Maleszewska, Stepińska U, Markowska M: Diurnal differences in melatonin effets on intracellulat $\mathrm{Ca}^{2+}$ concentration in chiscken spleen leukocytes in vitro. J. Pineal Res. 44:134-140, 2008.

Yerer MB, Aydogan S: The importance of circadian rhythm alterations in erythrocyte deformability. Clin. Hemorheol. Microcirc. 35:143-147, 2006.

Zak-Nejmark T, Nowak IA, Kraus-Filarska M: Circadian variations of histamine binding to lymphocytes and neutrophils and skin reactivity to histamine in atopic and healthy subjects. Arch. Immunol. Ther. Exper. (Warsz.) 54:283-287, 2006.

Zeman M, Vican M, Monosíková J, Herichová I: Deregulated expression of the per2 gene in human colorectal carcinoma. Mol. Med. Rep. 1: in press, 2008 